PANCREAS

\title{
Does anyone survive pancreatic ductal adenocarcinoma? A nationwide study re-evaluating the data of the Finnish Cancer Registry
}

\author{
M Carpelan-Holmström, S Nordling, E Pukkala, R Sankila, J LüHtges, G Klöppel, C Haglund
}

Gut 2005;54:385-387. doi: 10.1136/gut.2004.047191

\begin{abstract}
See end of article for authors' affiliations

.....................

Correspondence to: Dr C Haglund, Department of Surgery, Helsinki University Central Hospital, Finland PO Box 340, Helsinki, Fin-00029, Finland;

caj.haglund@hus.fi
\end{abstract}

Revised version received 20 August 2004 Accepted for publication 12 September 2004
Background: Worldwide survival data for ductal adenocarcinoma of the pancreas are the lowest among the 60 most frequent types of organ cancers. Hence published data on long time survivors of this disease are controversial. We performed a nationwide study comprising all Finnish patients diagnosed with pancreatic cancer in the period 1990-1996 who survived for at least five years after diagnosis.

Methods: Data on patients registered as five year survivors of pancreatic cancer were obtained from the Finnish Cancer Registry and Statistics Finland. Slides or paraffin blocks were collected from patients recorded as having histologically proven pancreatic ductal adenocarcinoma (PDAC) and were reevaluated in a double blind fashion by three pathologists with special expertise in pancreatic pathology. Results: Between 1990 and 1996, the Finnish Cancer Registry recorded 4922 pancreatic cancer patients, 89 of whom survived for at least five years. Reviewing this series of patients revealed 45 (49\%) non-PDACs and 18 cases without histological verification. In 26 patients recorded as having histologically proven PDAC, re-evaluation of histological specimens confirmed PDAC in only 10 patients.

Conclusions: This study indicates that (1) the prognosis of PDAC remains poor and (2) careful histopathological review of all patients with pancreatic cancer is mandatory if survival data are to be meaningful. l: Finland, pancreatic cancer constitutes approximately 3\% of all diagnosed cancers. However, it is the third and fourth most common cause of cancer death in females and males, respectively (www.cancerregistry.fi). More than 90\% of pancreatic cancers are ductal adenocarcinomas (PDAC), which are known for their extremely poor prognosis, whereas other types of pancreatic malignant tumours may have a more favourable prognosis. In many studies involving extensive surgery, the prognosis did not seem to be substantially influenced or improved. ${ }^{1-6}$ The reported values on long time survivors of PDAC have been questioned and it has been claimed that they are markedly lower than reported. While five year survival rates of $30-55 \%$ in PDAC patients treated with a curative intent have been published, ${ }^{7-11}$ reports of actual five year survival have usually been more modest, (approximately $10-20 \%$ for patients undergoing curative resection). ${ }^{12-16}$ Some series have failed to report any five year survivors ${ }^{17-19}$ and many authors believe that the actual values are close to zero. ${ }^{20-22}$

In order to obtain reliable non-biased data, we performed a nationwide study which included all Finnish patients diagnosed with pancreatic cancer $($ ICD $=$ C25) in 1990-1996 that had survived for at least five years after diagnosis.

\section{PATIENTS AND METHODS}

The Finnish Cancer Registry is a countrywide population based (population 5.1 million) register that collects data on all cancer cases in Finland. All hospitals and pathology and haematology laboratories as well as dentists submit mandatory data on cancer patients to the cancer registry. Additional data on survival and cause of death were obtained from Statistics Finland. The files were searched for patients diagnosed with pancreatic cancer $(\mathrm{ICD}=\mathrm{C} 25)$ from 1990 to 1996 who survived for more than five years. All slides or paraffin blocks (except for two cases) from patients recorded as having histologically proven PDAC were collected and re-evaluated in a double blind fashion by three pathologists with special expertise in pancreatic pathology (SN, Helsinki University Central Hospital, Finland; and JL and GK, University of Kiel, Germany).

\section{RESULTS}

According to the Finnish Cancer Registry, 4922 patients (2170 males) were diagnosed with pancreatic cancer $(\mathrm{ICD}=\mathrm{C} 25)$ from 1990 to 1996 . Eighty nine patients $(1.8 \%)$ were recorded as having survived for at least five years. Histological diagnoses based on the original records were obtained from the Finnish Cancer Registry (table 1). Half of the patients $(49 \%)$ had tumours other than PDAC. In 18 patients $(20 \%)$ the diagnosis of pancreatic cancer lacked histological confirmation and was based on clinical or cytological $(n=7)$ findings only. In four of seven patients with a cytology based diagnosis, smears were recorded as containing atypical cells suspicious for PDAC. Two of these patients died of cancer 5.03 and 5.09 years after diagnosis. In neither case was an autopsy performed. The third patient with positive cytology died 11.8 years after diagnosis. No cancer was detected at autopsy. The fourth patient is still alive 8.28 years after diagnosis. One of the long term survivors was erroneously reported as a cancer patient. She actually had a benign solid pseudopapillary neoplasm. In summary, more than two thirds $(70 \%)$ of the reported long term survivors of pancreatic cancer had either pancreatic tumours different from PDAC or were insufficiently documented (table 1).

From the remaining 26 patients recorded as having histologically proven PDAC, all slides or paraffin blocks (except for two cases) were collected and re-evaluated in a double blind fashion by three pathologists. More than half of the patients were found to have either pancreatic tumours

Abbreviations: PDAC, pancreatic ductal adenocarcinoma 
Table 1 Histological data from the Finnish Cancer Registry (1990-1996) for patients with pancreatic malignancies who survived for more than five years

\begin{tabular}{lrr}
\hline & $\mathbf{n}$ & $(\%)$ \\
\hline Ductal pancreatic adenocarcinoma & 26 & 29 \\
Mucinous cystadenocarcinoma & 7 & 8 \\
Ampullary or periampullary carcinoma & 12 & 13 \\
Endocrine tumours & 25 & 28 \\
Benign lesion & 1 & 1 \\
Solid pseudopapillary neoplasm & 1 & 1 \\
Cytology only & 7 & 8 \\
Benign cytology: endocrine tumour & 1 & 1 \\
Malignant cytology: endocrine tumour & 2 & 2 \\
Malignant cytology: adenocarcinoma & 4 & 4 \\
Neither histology nor cytology & 11 & 12 \\
Total & 89 & 100 \\
\hline
\end{tabular}

other than PDAC or non-neoplastic pancreatic changes (table 2). In only 10 patients could PDAC be confirmed. In nine cases it was in the head region and in one in the tail. All patients underwent curative R0 resection (one total pancreatectomy, eight pancreaticoduodenal resection, and one distal resection). Nine of the 10 patients died during follow up (median 5.4 years; range 5.08-13.4 years). Seven had tumour recurrence, one patient died of myocardial infarction, and one of a subdural haematoma. Interestingly, two of seven patients who died of tumour recurrence had lymph node metastases at the time of the primary diagnosis. At the end of follow up on 1 August 2003, one patient was still alive and disease free (follow up time 13.4 years). This PDAC was a small stage IB grade I tumour in the pancreatic head.

\section{DISCUSSION}

Our data showed that in Finland, during the period 19901996, only 10 patients with histologically proven PDAC survived for more than five years. During this period, 4922 cases of pancreatic cancer were recorded. As approximately $90 \%$ of pancreatic cancers are considered to be PDAC, the overall five year survival of PDAC patients was only $0.2 \%$. Surgery has been considered the only chance for long term survival of PDAC patients but not even radical surgery, including extended lymphadenectomy, has convincingly improved the overall survival in PDAC patients. ${ }^{45}$ A nationwide Finnish study recently reported 163 Whipple procedures for PDAC between 1990 and 1994. ${ }^{23}$ As seven of the 10 long term survivors in our study had been treated during that time period, the five year nationwide survival for patients who underwent a Whipple procedure for PDAC in 1990-1994 was $4.3 \%$. It should be noted that histology of the PDACs in this study was not re-evaluated, unlike in our study. Thus the number of Whipple operations performed for true PDAC may be lower and consequently the rate of five year survivors somewhat higher. The five year survival rate after a Whipple procedure has been reported to be approximately $5 \%$ in other studies ${ }^{24-27}$ although there are also several reports with better long term results, especially those performed in single institutions..$^{7-16}{ }^{28-30}$ Adjuvant chemotherapy may also have a significant survival benefit in patients with resected pancreatic cancer. ${ }^{31}$ With more patients now surviving the operation, due at least in part to concentration of pancreatic cancer surgery in large specialised multidisciplinary units, one would expect an increase in long term survivors.

This nationwide study confirms the poor prognosis of PDAC on a national scale. The only long term survivor who is alive today had an early stage grade I carcinoma, features known to be associated with the most favourable outcome. The remaining five year survivors in this study did not exhibit distinguishing morphological features that predicted the favourable outcome and two PDAC patients with initial lymph node metastases survived for five years. An important finding was that survival for five years does not guarantee definitive survival. In common with many other cancers, deaths from recurrent disease can occur more than five years after the initial operation.

Our results also support the commonly expressed doubts that published data on survival in pancreatic cancer might not always represent actual survival of PDAC patients. Studies may be based on unreliable histological classification and thus include patients with other types of pancreatic malignancies or even patients with benign diseases. In a study by Nitecki et al, pathological re-review led to a change in diagnosis in 12 of 186 patients who underwent pancreatic resection for PDAC. ${ }^{18}$ Similarly, Trede et al reclassified $6 \%$ of their patients after reviewing pathological specimens. ${ }^{10}$ Connolly et al reported only 11 out of 23 three year survivors of pancreatic cancer after histologically confirmed disease. ${ }^{25}$ Conlon et al noted that without histological re-evaluation of their PDAC material, the five year survival rate would have been $19 \%$ instead of the reported $10.2 \% .{ }^{13}$ We therefore conclude that a thorough histopathological re-evaluation of all specimens from patients with PDAC is mandatory to obtain reliable data on follow up and survival. Another reason for overly optimistic survival results might be skewed statistical description of the results and publication of survival values without information on the number of actual survivors and a clear definition of the subset. ${ }^{21}$

Table 2 Histological re-evaluation of 26 patients who, according to the Finnish Cancer Registry, were diagnosed with pancreatic ductal adenocarcinoma between 1990 and 1996 and survived for at least 5 years

\begin{tabular}{|c|c|c|c|}
\hline & $\mathbf{n}$ & (\%) & Follow up data \\
\hline Verified ductal adenocarcinoma & 10 & 38 & \\
\hline Stage IA (TI NO MO) & 1 & 4 & 1 DCR (5.48 y) \\
\hline Stage IB (T2 NO MO) & 5 & 19 & $3 \mathrm{DCR}(5.10-5.86 y), 1 \mathrm{DOD}(5.06 \mathrm{y}), 1 \mathrm{AWC}(13.4 \mathrm{y})$ \\
\hline Stage IIA (T3 NO MO) & 2 & 8 & 1 DCR $(5.31$ y), 1 DOD $(6.20 y)$ \\
\hline Stage IIB (T2-3N1MO) & 2 & 8 & 2 DCR $(5.12-5.59$ y) \\
\hline Wrong diagnosis & 14 & 54 & \\
\hline Intraductal papillary-mucinous neoplasm & 2 & 8 & \\
\hline Solid pseudopapillary neoplasm & 1 & 4 & \\
\hline Pancreatitis & 2 & 8 & \\
\hline Serous cystadenoma & 1 & 4 & \\
\hline Common bile duct carcinoma & 1 & 4 & \\
\hline Ampullary/periampullary carcinoma & 7 & 27 & \\
\hline Histological material not available & 2 & 8 & \\
\hline Total & 26 & 100 & \\
\hline
\end{tabular}


In conclusion, a common reason for long term survival of PDAC patients is an initial false diagnosis. However, it is possible to survive for five or even 10 years after a diagnosis of PDAC, although this is rare. As there is now a general trend towards concentration of pancreatic cancer surgery in specialised multidisciplinary units, the number of initial false diagnoses should decrease. Whether concentration of pancreatic cancer surgery services in combination with adjuvant chemotherapy improves the poor long term survival of PDAC patients remains to be seen.

\section{ACKNOWLEDGEMENTS}

M Carpelan-Holmström and C Haglund designed, coordinated, and managed the study. E Pukkala and R Sankila provided the patient data from the Finnish Cancer Registry. S Nordling, J Lüttges, and G Klöppel re-evaluated the histological slides of the resected pancreatic cancer tissue specimens. M Carpelan-Holmström and C Haglund wrote the report, with contributions from all other authors. M Carpelan-Holmström and C Haglund had full access to all data in the study and had final responsibility for the decision to publish. The Finnish Research Group thank the organisers of the Pancreas 2000 project, which is an educational and research programme for scientists in the UK, Germany, and the Nordic and Baltic countries interested in pancreatic disorders, for introducing us to our German collaborators, J Lüttges and G Klöppel.

We thank the staff of the Finnish hospitals for providing patient records and histopathological material for the study. The skilful technical assistance of Ms. Elina Laitinen, Ms Päivi Peltokangas, and Ms Elina Malkki is acknowledged. This study was supported by grants from the Helsinki University Central Hospital Research Foundation, Finska Läkaresällskapet, and Medicinska Understödsföreningen Liv och Hälsa. The funding sources had no role in study design, data collection, data analysis, data interpretation, or writing of the report.

\section{Authors' affiliations}

M Carpelan-Holmström, C Haglund, Department of Surgery, Helsinki

University Central Hospital, Finland

S Nordling, Department of Pathology, Helsinki University Central Hospital, Finland

E Pukkala, R Sankila, Finnish Cancer Registry, Helsinki, Finland J Lüttges, G Klöppel, Department of Pathology, University of Kiel, Germany

Conflict of interest: None declared.

\section{REFERENCES}

1 Manabe T, Ohshio G, Baba N, et al. Radical pancreatectomy for ductal cell carcinoma of the head of the pancreas. Cancer 1989:64:1132-7.

2 Ishikawa O, Ohigashi H, Sasaki Y, et al. Practical grouping of positive lymph nodes in pancreatic head cancer treated by an extended pancreatectomy. Surgery 1997; 121:244-9.

3 Ishikawa O, Óhhigashi H, Sasaki Y, et al. Practical usefulness of lymphatic and connective tissue clearance for the carcinoma of the pancreas head. Ann Surg 1988;208:215-20.

4 Yeo CJ, Cameron JL, Maher MM, et al. A prospective randomized trial of pancreaticogastrostomy versus pancreaticojejunostomy after pancreaticoduodenectomy. Ann Surg 1995;222:580-8.

5 Pedrazzoli S, DiCarlo V, Dionigi R, et al. Standard versus extended lymphadenectomy associated with pancreatoduodenectomy in the surgical treatment of adenocarcinoma of the head of the pancreas: a multicenter, prospective, randomized study. Lymphadenectomy Study Group. Ann Surg 1998;228:508-17

6 Capussotti L, Massucco P, Ribero D, et al. Extended lymphadenectomy and vein resection for pancreatic head cancer: outcomes and implications for therapy. Arch Surg 2003;138:1316-22.

7 Kayahara M, Nagakawa T, Ueno K, et al. Surgical strategy for carcinoma of the pancreas head area based on clinicopathologic analysis of nodal involvement and plexus invasion. Surgery 1995;117:616-23.

8 Delcore R, Thomas JH, Hermreck AS. Pancreaticoduodenectomy for malignant pancreatic and periampullary neoplasms in elderly patients. Am J Surg $1991 ; 162: 532-5$

9 Nagakawa T, Nagamori M, Futakami F, et al. Results of extensive surgery for pancreatic carcinoma. Cancer 1996:77:640-5.

10 Trede M, Schwall G, Saeger HD. Survival after pancreatoduodenectomy. 118 consecutive resections without an operative mortality. Ann Surg 1990;211:447-58.

11 Tsuchiya R, Noda T, Harada N, et al. Collective review of small carcinomas of the pancreas. Ann Surg 1986;203:77-81.

12 Cleary SP, Gryfe R, Guindi M, et al. Prognostic factors in resected pancreatic adenocarcinoma: analysis of actual 5-year survivors. J Am Coll Surg 2004; 198:722-31

13 Conlon KC, Klimstra DS, Brennan MF. Long-term survival after curative resection for pancreatic ductal adenocarcinoma. Clinicopathologic analysis of 5-year survivors. Ann Surg 1996;223:273-9.

14 Sperti C, Pasquali C, Piccoli A, et al. Survival after resection for ductal adenocarcinoma of the pancreas. Br J Surg 1996;83:625-31.

15 Sohn TA, Yeo CJ, Cameron JL, et al. Resected adenocarcinoma of the pancreas -616 patients: results, outcomes, and prognostic indicators. J Gastrointest Surg 2000;4:567-79.

16 Yeo CJ, Sohn TA, Cameron JL, et al. Periampullary adenocarcinoma: analysis of 5-year survivors. Ann Surg 1998;227:821-31.

17 Wade TP, el-Ghazzawy AG, Virgo KS, et al. The Whipple resection for cancer in U.S. Department of Veterans Affairs Hospitals. Ann Surg 1995;221:241-8

18 Nitecki SS, Sarr MG, Colby TV, et al. Long-term survival after resection for ductal adenocarcinoma of the pancreas. Is it really improving? Ann Surg 1995;221:59-66.

19 Carcinoma of the pancreas: a retrospective review. J Surg Oncol 1990;45:184-9.

20 Alanen KA, Joensuu $\mathrm{H}$. Long-term survival after pancreatic adenocarcinoma-often a misdiagnosis? Br J Cancer 1993:68:1004-5.

21 Gudjonsson B. Survival statistics gone awry: pancreatic cancer, a case in point. J Clin Gastroenterol 2002;35:180-4.

22 Gudjonsson B. Cancer of the pancreas. 50 years of surgery. Cancer 1987; 60:2284-303.

23 Nordback L, Parviainen M, Raty S, et al. Resection of the head of the pancreas in Finland: effects of hospital and surgeon on short-term and long-term results. Scand J Gastroenterol 2002;37:1454-60.

24 Grace PA, Pitt HA, Longmire WP. Pancreatoduodenectomy with pylorus preservation for adenocarcinoma of the head of the pancreas. Br J Surg 1986;73:647-50

25 Connolly MM, Dawson PJ, Michelassi F, et al. Survival in 1001 patients with carcinoma of the pancreas. Ann Surg 1987;206:366-73.

26 Lerut JP, Gianello PR, Otte JB, et al. Pancreaticoduodenal resection. Surgical experience and evaluation of risk factors in 103 patients. Ann Surg 1984; 199:432-7.

27 Lerut JP, Gianello PR, Otte JB. Cancer of the pancreas: a dilemma in treatment. Surg Clin North Am 1981;61:107-15.

28 Sarr MG, Behrns KE, van Heerden JA. Total pancreatectomy. An objective analysis of its use in pancreatic cancer. Hepatogastroenterology 1993;40:418-21.

29 Baumel H, Huguier M, Manderscheid JC, et al. Results of resection for cancer of the exocrine pancreas: a study from the French Association of Surgery. Br J Surg 1994:81:102-7.

30 Klempnauer J, Ridder GJ, Bektas $\mathrm{H}$, et al. Extended resections of ductal pancreatic cancer-impact on operative risk and prognosis. Oncology 1996;53:47-53.

31 Neoptolemos JP, Stocken DD, Friess H, et al. A randomized trial of chemoradiotherapy and chemotherapy after resection of pancreatic cancer. N Engl J Med 2004;350:1200-10. 